\title{
A copper(I)-catalyzed sulfonylative Hiyama cross-coupling
}

Aurélien Adenot, ${ }^{[a]}$ Lucile Anthore-Dalion, ${ }^{[a]}$ Emmanuel Nicolas, ${ }^{[a]}$ Jean-Claude Berthet, ${ }^{[a]}$ Pierre Thuéry, ${ }^{[a]}$ and Thibault Cantat*[a]

[a] Dr A. Adenot, Dr L. Anthore-Dalion, Dr E. Nicolas, Dr P. Thuéry, Dr T. Cantat, Université ParisSaclay, CEA, CNRS, NIMBE, 91191 Gif-sur-Yvette, France. E-mail: thibault.cantat@cea.fr

\begin{abstract}
An air-tolerant $\mathrm{Cu}$-catalyzed sulfonylative Hiyama cross-coupling reaction enabling the formation of diaryl sulfones is described. Starting from aryl silanes, DABSO and aryliodides, the reaction tolerates a large variety of polar functional groups (amines, ketones, esters, aldehydes). Control experiments coupled with DFT calculations shed light on the mechanism, where the reductive elimination showcases an usual high energy barrier for a $\mathrm{Cu}(\mathrm{III}) / \mathrm{Cu}(\mathrm{I})$ process.
\end{abstract}

\section{Introduction}

Transition metal-catalyzed cross-coupling reactions of organometallic reagents with electrophilic coupling partners represent one of the most powerful methods to generate carbon-carbon and carbonheteroatom bonds, and therefore, stand out as key methods in organic synthesis over the past decades. ${ }^{1}$ Besides, three-component coupling reactions in which a small molecule is inserted between the nucleophile and the electrophile partners permit to increase the molecular complexity of products in an atom-economical way. While the insertion of carbon monoxide has been extensively exploited to prepare carbonyl derivatives, ${ }^{2}$ much less attention has been given to sulfur dioxide. ${ }^{3}$ Yet, the resulting sulfones are known to have a prominent biological activity as well as an important synthetic utility, making sulfonylative couplings particularly attractive..$^{4,5}$

From all commonly used organometallic reagents, organosilanes are presumably among the most appealing ones. In addition to being readily available, air-stable and relatively non-toxic, they display an improved functional-group tolerance compared to organolithium or -magnesium, thanks to their low nucleophilicity. ${ }^{6}$ Recently, we described the first Pd-catalyzed sulfonylative Hiyama cross-coupling with $\mathrm{sp}^{2}$-hybridized electrophiles. ${ }^{7}$ Surprisingly, only allylsilanes were found to react with sulfur dioxide, arylsilanes being inert under the reaction conditions. A careful mechanistic study unveiled that the organosilane was not involved in a transmetalation step, but instead reacting through a $S_{E} 2$ ' mechanism, restricting the scope to the formation of allyl aryl sulfones. We therefore sought to develop a system able to unlock the conversion of arylsilanes to diaryl sulfones through a sulfonylative Hiyama coupling, for the first time.

Wu et al. reported in 2016 that both alkyl- and aryl(trialkoxy)silanes were able to transmetalate with a $\mathrm{Cu}(\mathrm{I})$-catalyst and thereafter insert sulfur dioxide in the newly formed $\mathrm{Cu}-\mathrm{C}$ bond (Scheme 1a). ${ }^{8}$ However, the resulting sulfinate was only able to react with aliphatic electrophiles through an $S$-alkylation reaction. Meanwhile, $\mathrm{Cu}(\mathrm{I})$-catalysts were shown to promote the coupling of sulfinates, either preformed or in situ synthetized from arylboronic acids, with aryl halides (Scheme $1 \mathrm{~b}$ and $1 \mathrm{c}$, respectively). ${ }^{3,9}$ These encouraging precedents, added to the low price and toxicity of copper, have prompted us to investigate and disclose herein a $\mathrm{Cu}(\mathrm{I})$-catalyzed sulfonylative Hiyama cross-coupling enabling the formation of diaryl sulfones (Scheme 1d). 
(a) 2016 - Wu et al. - S-alkylation of the sulfinate

$$
\begin{aligned}
& \mathrm{Cu}_{2} \mathrm{O}(10 \mathrm{~mol} \%) \\
& \mathrm{R}-\mathrm{Si}(\mathrm{OEt})_{3}+\mathrm{SO}_{2} "+\mathrm{Br}-\mathrm{Alkyl} \frac{\mathrm{CsF}(2 \mathrm{eq} .)}{\mathrm{H}_{2} \mathrm{O} / \mathrm{DMF}, 100^{\circ} \mathrm{C}, 12 \mathrm{~h}} \stackrel{\mathrm{R}^{-}}{\stackrel{\mathrm{O}}{\mathrm{S}} \text {-Alkyl }} \\
& \mathrm{R}=\mathrm{alkyl}, \mathrm{ary} \mid
\end{aligned}
$$

(b) 2005 - Ma et al. - Cross-coupling of a preformed sulfinate

$$
\begin{array}{ccc}
\text { Cul (10 mol\%) } & \text { L-proline (sodium salt, 20 mol\%) } \\
\text { DMSO, } 80-95^{\circ} \mathrm{C}, 24-48 \mathrm{~h} & \mathrm{X}=\mathrm{I}, \mathrm{Br} & \begin{array}{l}
\mathrm{R}=\mathrm{Me}, \mathrm{Ph} \\
\text { (Het) } \mathrm{Ar}=\text { (hetero)aryl }
\end{array}
\end{array}
$$

(c) 2017 - Willis et al. - Sulfonylative Suzuki cross-coupling

$$
\mathrm{Ar}^{1}-\mathrm{B}(\mathrm{OH})_{2}+\mathrm{SO}_{2} "+1-\mathrm{Ar}^{2} \frac{\left[\mathrm{Cu}(\mathrm{MeCN})_{4}\right] \mathrm{BF}_{4}(10 \mathrm{~mol} \%)}{\text { ligand }(10 \mathrm{~mol} \%)} \begin{aligned}
& \mathrm{DMPU}, 110{ }^{\circ} \mathrm{C}, 36 \mathrm{~h} \\
& \text { ligand }=4,4^{\prime} \text {-dimethoxy-2,2'-bipyridine }
\end{aligned} \mathrm{Ar}^{1} \mathrm{Ar}^{2}
$$

(d) This work: Copper-catalyzed sulfonylative Hiyama cross-coupling

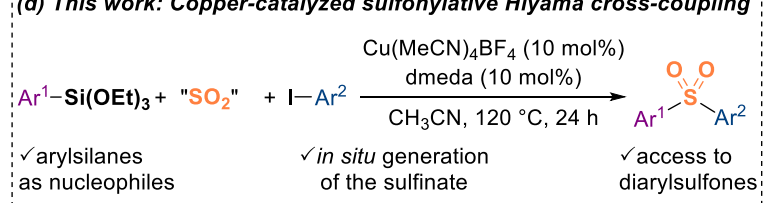

Scheme 1. Sulfinates formation from organosilanes (a) and coupling with aryl iodides (b and c) under copper-catalyzed reaction conditions. DABSO = 1,4-diazabicyclo[2.2.2]octane bis(sulfur dioxide); dmeda =1,2-dimethyl ethylenediamine.

\begin{tabular}{|c|c|c|c|c|c|}
\hline & & 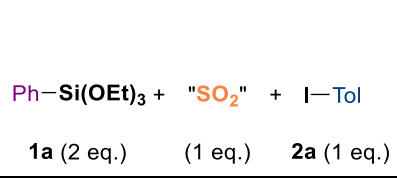 & $\begin{array}{c}\begin{array}{c}{[\mathrm{Cu}](10 \mathrm{~mol} \%)} \\
\text { ligand }(10 \mathrm{~mol} \%) \\
{\left[\mathrm{F}^{\Theta}\right](1 \mathrm{eq} .)}\end{array} \\
\mathrm{CH}_{3} \mathrm{CN}, 120^{\circ} \mathrm{C}, 6 \mathrm{~h}\end{array}$ & 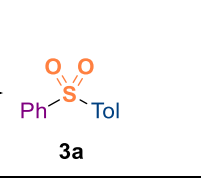 & \\
\hline Entry & $" \mathrm{SO}_{2} "$ & $\mathrm{~F}^{-}$source & {$[\mathrm{Cu}]$} & Ligand & Yield $^{a}$ \\
\hline 1 & DABSO & TBAF ( $1 \mathrm{M}$ in THF) & {$\left[\mathrm{Cu}(\mathrm{MeCN})_{4}\right] \mathrm{BF}_{4}$} & bipy & $55 \%$ \\
\hline 2 & $\mathrm{SO}_{2}$ & TBAF (1 M in THF) & {$\left[\mathrm{Cu}(\mathrm{MeCN})_{4}\right] \mathrm{BF}_{4}$} & bipy & $27 \%$ \\
\hline 3 & DABSO & TBAF. $3 \mathrm{H}_{2} \mathrm{O}$ & {$\left[\mathrm{Cu}(\mathrm{MeCN})_{4}\right] \mathrm{BF}_{4}$} & bipy & $55 \%$ \\
\hline $4^{b}$ & DABSO & $\mathrm{TBAF} \cdot 3 \mathrm{H}_{2} \mathrm{O}$ & {$\left[\mathrm{Cu}(\mathrm{MeCN})_{4}\right] \mathrm{BF}_{4}$} & bipy & $54 \%$ \\
\hline 5 & DABSO & TBAF. $3 \mathrm{H}_{2} \mathrm{O}$ & Cul & bipy & $31 \%$ \\
\hline 6 & DABSO & $\mathrm{TBAF} \cdot 3 \mathrm{H}_{2} \mathrm{O}$ & $\mathrm{Cu}(\mathrm{OAc})_{2}$ & bipy & $18 \%$ \\
\hline 7 & DABSO & TBAF $\cdot 3 \mathrm{H}_{2} \mathrm{O}$ & {$\left[\mathrm{Cu}(\mathrm{MeCN})_{4}\right] \mathrm{BF}_{4}$} & $\mathrm{acac}^{-}$ & $48 \%$ \\
\hline 8 & DABSO & $\mathrm{TBAF} \cdot 3 \mathrm{H}_{2} \mathrm{O}$ & {$\left[\mathrm{Cu}(\mathrm{MeCN})_{4}\right] \mathrm{BF}_{4}$} & phen & $65 \%$ \\
\hline 9 & DABSO & TBAF $3 \mathrm{H}_{2} \mathrm{O}$ & {$\left[\mathrm{Cu}(\mathrm{MeCN})_{4}\right] \mathrm{BF}_{4}$} & dmeda & $69 \%$ \\
\hline $10^{c}$ & DABSO & $\mathrm{TBAF} \cdot 3 \mathrm{H}_{2} \mathrm{O}$ & {$\left[\mathrm{Cu}(\mathrm{MeCN})_{4}\right] \mathrm{BF}_{4}$} & dmeda & $98 \%$ \\
\hline $11^{\mathrm{c}, \mathrm{d}}$ & DABSO & TBAF. $3 \mathrm{H}_{2} \mathrm{O}$ & {$\left[\mathrm{Cu}(\mathrm{MeCN})_{4}\right] \mathrm{BF}_{4}$} & dmeda & $97 \%(87 \%)$ \\
\hline 12 & DABSO & TBAF $\cdot 3 \mathrm{H}_{2} \mathrm{O}$ & - & - & $0 \%$ \\
\hline
\end{tabular}

\section{Results and Discussion}

We began our investigation by exploring the coupling of triethoxy(aryl)silane (1a), 4-iodotoluene (2a), and $\mathrm{DABCO}\left(\mathrm{SO}_{2}\right)_{2}$ (named $\mathrm{DABSO}$ ), a commercial surrogate of sulfur dioxide, popularized by Willis and co-workers. ${ }^{10-12}$ In the presence of a catalytic amount of $\mathrm{Cu}(\mathrm{MeCN})_{4} \mathrm{BF}_{4}, 2,2$ '-bipyridine and tetrabutylammonium fluoride (TBAF, $1 \mathrm{~m}$ solution in THF) as an anhydrous fluoride source to activate organosilane 1a, the reaction gave the desired sulfone $3 \mathrm{a}$ in $55 \%$ yield after $6 \mathrm{~h}$ at $120^{\circ} \mathrm{C}$ under inert atmosphere (Table 1, entry 1 ).

Table 1. Influence of the reaction conditions on the sulfonylative Hiyama cross-coupling of phenyl(triethoxy)silane (1a) with 4iodotoluene (2a) (see ESI for a more exhaustive table). ${ }^{[a]}$

[a] Standard reaction conditions: 1 a $(0.2 \mathrm{mmol}, 2$ eq. $)$, $\mathrm{SO}_{2}$ " $(0.1 \mathrm{mmol}, 1$ eq. $), 2 \mathrm{a}(0.1 \mathrm{mmol}, 1$ eq. $)$, fluoride source $(0.1 \mathrm{mmol}$, 1 eq.), [Cu] (0.01 mmol, $10 \mathrm{~mol} \%)$, ligand $(0.01 \mathrm{mmol}, 10 \mathrm{~mol} \%), \mathrm{CD}_{3} \mathrm{CN}(0.4 \mathrm{~mL})$, Ar atmosphere, $120^{\circ} \mathrm{C}, 6 \mathrm{~h}$. Yields were measured by ${ }^{1} \mathrm{H}$ NMR (internal standard: mesitylene). The number within parentheses is the isolated yield from a $1.0 \mathrm{mmol}$ scale reaction. [b] Air atmosphere was used instead of Ar. [c] Reaction was left for $24 \mathrm{~h}$ instead of $6 \mathrm{~h}$. [d] Only $1.25 \mathrm{eq}$. of 1a were used. bipy $=2,2^{\prime}$-bipyridine, acac $^{-}=$acetylacetonate anion, phen $=1,10$-phenanthroline, dmeda $=N, N^{\prime}$-dimethyl ethylenediamine. 
By contrast, gaseous sulfur dioxide, generated by thermal decomposition of $\mathrm{K}_{2} \mathrm{~S}_{2} \mathrm{O}_{5}$ in a two-chamber apparatus, led to a lower yield $(27 \%$, Table 1 , entry 2$)$ under the same conditions. When the benchstable TBAF $3 \mathrm{H}_{2} \mathrm{O}$ was used instead of the anhydrous THF solution, no change was observed in the yield, demonstrating some tolerance of the reaction towards water (Table 1, entry 3 ). Besides, the reaction was also shown to be air-tolerant (Table 1, entry 4). No better results were obtained with another source of copper (including $\mathrm{Cu}$ (II) salts, Table 1, entries 5 and 6), probably because of a greater solubility of $\mathrm{Cu}(\mathrm{MeCN})_{4} \mathrm{BF}_{4}$. A variety of different ligands employed in Cu-catalyzed C-heteroatom bond formation ${ }^{13-15}$ were explored, mainly bidentate $\mathrm{N}, \mathrm{N}-, \mathrm{N}, \mathrm{O}$ - and $\mathrm{O}, \mathrm{O}$-ligands (Table 1, entries 7, 8, 9 and Table S5). $N, N^{\prime}$-dimethylethylenediamine (dmeda) gave the best results, yielding the desired sulfone in $98 \%$ yield after $24 \mathrm{~h}$ at $120^{\circ} \mathrm{C}$ (Table 1 , entry 10). Using only 1.25 equivalent of the silane led to the same yield $(97 \%$, Table 1, entry 11). No product was observed without the catalyst (Table 1, entry 12) and a decrease in temperature $\left(100^{\circ} \mathrm{C}\right)$ led to lower yields, the ESI provides full details of the optimization study (see ESI 1.2). Interestingly, no formation of the direct $\mathrm{C}-\mathrm{C}$ cross-coupling product was observed under these conditions.

With the optimized reaction conditions in hand, we next explored the scope of the sulfonylation of various organic halides (Scheme 2). First, one can notice a good tolerance of the reaction to electron-donating groups (3a-h, 60-87\%). Interestingly, halides $\mathbf{2 c}$ and $\mathbf{2 d}$ bearing either an unprotected amine or an alcohol group provided the desired products with good yields ( $85 \%$ and $75 \%$, respectively), without observation of any side $\mathrm{C}-\mathrm{N}$ or $\mathrm{C}-\mathrm{O}$ coupling. Besides, variation of the position of the methyl group on iodotoluene (2a, $\mathbf{2} \mathbf{e}$ and $\mathbf{2 f})$ as well as the use of a bicyclic halide $(\mathbf{3 g})$ show a moderate influence of steric hindrance on the reaction outcome (isolated yields 60-87\%). In addition, electron-withdrawing groups could also be incorporated, leading to compounds $3 \mathbf{i}-\mathbf{p}$ in moderate yields (35-62\%). It is noteworthy that a broad range of useful functionalities could be introduced, including fluorides and chlorides (3i-k, 43-62\%) and some sensitive carbonyl moieties such as aldehyde (3m, 35\%), ketone (3n, 64\%), amide (3o, 42\%), or ester (3p, 61\%). Finally, heterocyclic electrophiles featuring pyridyl (2q) and thiophenyl (2r) moieties have also been used successfully, giving product yields of 42 and $48 \%$, respectively.

(

Scheme 2. Substrate scope in organohalides. Reaction conditions: phenyl(triethoxy)silane (1a, $1.25 \mathrm{mmol}, 1.25$ eq.), electrophile ( $1.0 \mathrm{mmol}, 1.0$ eq.), DABSO (0.50 mmol, 0.50 eq.), TBAF. $3 \mathrm{H}_{2} \mathrm{O}$ (1.0 mmol, 1.0 eq.), $\mathrm{Cu}(\mathrm{MeCN})_{4} \mathrm{BF}_{4}(0.10 \mathrm{mmol}, 10 \mathrm{~mol} \%)$, dmeda $(0.10 \mathrm{mmol}, 10 \mathrm{~mol} \%), \mathrm{CH}_{3} \mathrm{CN}(4 \mathrm{~mL}), 120^{\circ} \mathrm{C}, 24 \mathrm{~h}$. Isolated yields. Yields within parentheses were measured by ${ }^{1} \mathrm{H}$ NMR on $0.1 \mathrm{mmol}$ scale (internal standard: mesitylene)

A range of aryl(triethoxy)silanes 1 was examined (Scheme 3), showing that the reaction tolerates electron-donating groups (3s-u, $75-81 \%)$ and, to a lesser extent, electron-withdrawing ones (3v and $\mathbf{3} \mathbf{w}$, 
39 and $51 \%$, respectively). More hindered substrates such as 1-naphtyl(triethoxy)silane also proceeded to give the desired sulfone $3 x$ in $41 \%$ yield. Siloxane 1', synthesized by direct silylation of benzene with an hydrosilane through $\mathrm{C}-\mathrm{H}$ bond activation, ${ }^{16}$ gave the desired diaryl sulfone $3 \mathbf{3 a}$ in $35 \%$ yield.

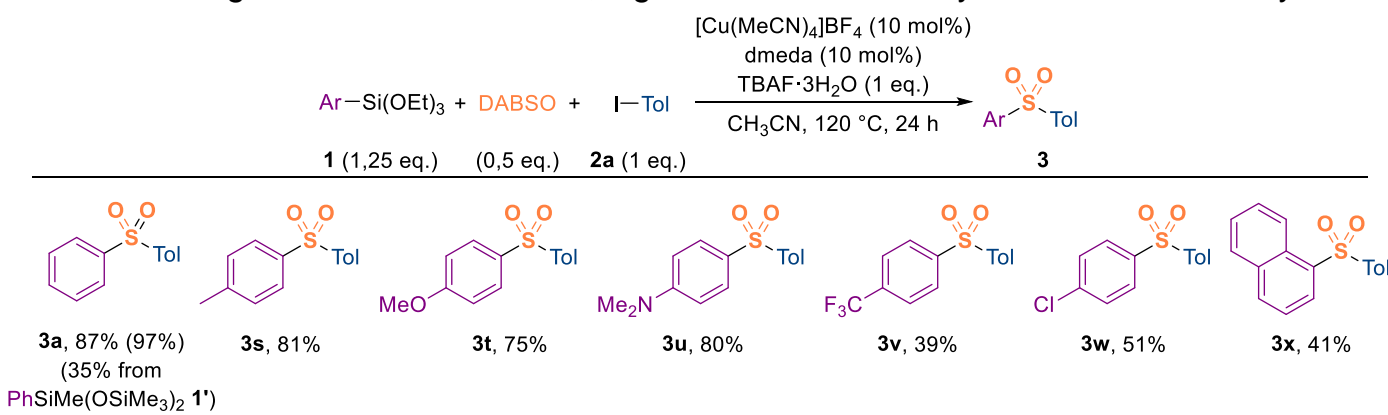

Scheme 3. Substrate scope in organohalides. Reaction conditions: organosilane (1.25 mmol, 1.25 eq.), 4-iodotoluene (2a, $1.0 \mathrm{mmol}, 1.0$ eq.), DABSO (0.50 mmol, 0.50 eq.), TBAF $3 \mathrm{H}_{2} \mathrm{O}\left(1.0 \mathrm{mmol}, 1.0\right.$ eq.), $\mathrm{Cu}(\mathrm{MeCN})_{4} \mathrm{BF}_{4}(0.10 \mathrm{mmol}, 10 \mathrm{~mol} \%)$, dmeda $(0.10 \mathrm{mmol}, 10 \mathrm{~mol} \%), \mathrm{CH}_{3} \mathrm{CN}(4 \mathrm{~mL}), 120^{\circ} \mathrm{C}, 24 \mathrm{~h}$. Isolated yields. Yields within parentheses were measured by ${ }^{1} \mathrm{H}$ NMR on $0.1 \mathrm{mmol}$ scale (internal standard: mesitylene).

To unravel the key features of the reaction, and in particular to understand the formation of both $\mathrm{C}-\mathrm{S}$ bonds, the activation of the electrophile and disclose the rate-determining process, we carried out both experimental and computational mechanistic studies. The formation of the first $\mathrm{C}-\mathrm{S}$ bond was supposed to occur after a halogen exchange on the metal to furnish a Cu-F intermediate, which, upon transmetalation with the nucleophile, followed by $\mathrm{SO}_{2}$ insertion, yields a copper(I) sulfinate intermediate (Scheme 4a), as described by the group of Wu (Scheme 1a). ${ }^{8}$ Oxidative addition of the latter in the electrophile Arl, followed by reductive elimination would lead to the formation of the second $\mathrm{C}-\mathrm{S}$ bond, release of the diarylsulfone and regeneration of the catalyst.

Different mechanisms have been reported for the activation of the aryl halide with Cu-complexes, featuring a one- or two-electron process. Although the $\mathrm{Cu}(\mathrm{I}) / \mathrm{Cu}(\mathrm{III})$ cycle through oxidative addition/reductive elimination is the most commonly reported mechanism for the modified Ullmann reaction, ${ }^{17}$ experimental and computational data do not converge into a single mechanism and the radical pathway has also shown to be viable. ${ }^{18}$ Here, the dependence of the reaction efficiency on the nature of the leaving halogen for the formation of compound $3 \mathrm{a}$ on $0.1 \mathrm{mmol}$ scale from aryl-iodide $(97 \%)$, bromide $(33 \%)$ and chloride (traces) hinted at an ionic mechanism (Scheme 2). To confirm this statement, we decided to explore the formation of a sulfone product by reaction between a copper(I)sulfinate complex and an electrophile.

To avoid solubility issues, the study was performed with 1,10-phenanthroline (phen) as a ligand. The sulfinate dimer $\left[(\text { phen }) \mathrm{Cu}\left(\mathrm{SO}_{2} \mathrm{Tol}\right)\right]_{2}$ (4) was synthesized from $(\mathrm{CuOtBu})_{4}$, treated with 1,10phenanthroline, followed by 4-toluenesulfinic acid in THF at room temperature (Scheme 4b). Complex 4 crystallized in hot acetonitrile in the form of a dimer with ( $\mu-\mathrm{SO}_{2} \mathrm{Ar}-\mathrm{kO}: \mathrm{KS}$ )-coordination, in accordance with its infrared spectrum, and as already observed for some $\mathrm{Pd}(\mathrm{II})-{ }^{19}$ and $\mathrm{Cu}(\mathrm{II})$-sulfinate ${ }^{20}$ complexes. The stoichiometric coupling of $\mathbf{4}$ with 2-(allyloxy)iodobenzene (5) led to the exclusive formation of sulfone $6 \mathbf{a}$ in $79 \%$ yield (Scheme $4 \mathrm{c}$ ), providing further evidence for an ionic mechanism. In the case of a radical mechanism, the fast cyclization of the putative aryl radical intermediate would indeed have generated cyclized products such as $\mathbf{6 b}$ or $\mathbf{6 c} .^{21-23}$ 
a)

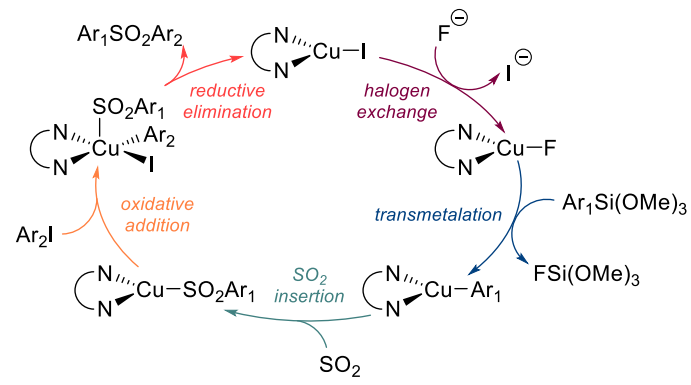

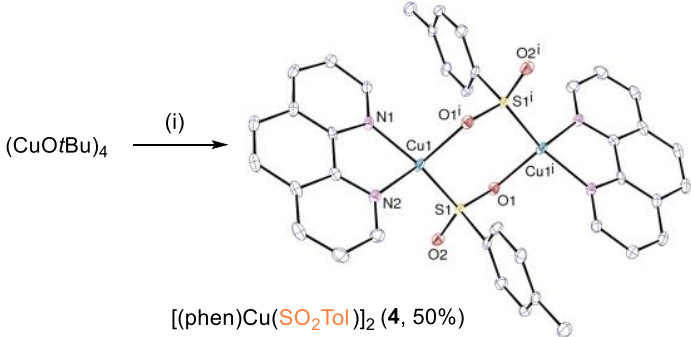

(i) 1) phenanthroline (3.6 eq.), $\left.\mathrm{THF}, 23^{\circ} \mathrm{C} ; 2\right) \mathrm{TolSO}_{2} \mathrm{H}$ (3.8 eq.), $\mathrm{THF}, 23^{\circ} \mathrm{C}$ (Crystal structure obtained in hot acetonitrile)

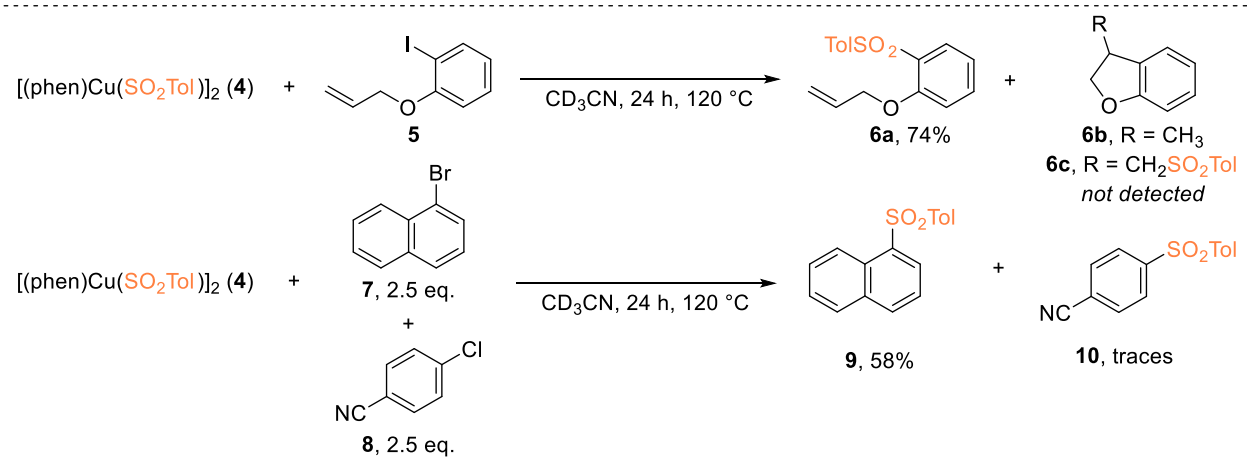

Scheme 4. (a) Proposed pathway for the mechanism of the reaction. (b) Synthesis of $\left.\left[(p h e n) \mathrm{Cu}_{(\mathrm{SO}}-\mathrm{C}_{6} \mathrm{H}_{4}-\mathrm{CH}_{3}\right)\right]_{2}(4)$. (c) Mechanistic control experiments: radical clock experiment with 2-(allyloxy)iodobenzene and substrate-competition study between 1-bromonaphthalene and 4-chlorobenzonitrile. Yields measured by ${ }^{1} \mathrm{H}$ NMR (internal standard: mesitylene).

A last control experiment withstanding a concerted cleavage of the electrophile is the competition coupling between copper-sulfinate 4 and two electrophiles: 1-bromonaphthalene (7) and 4chlorobenzonitrile (8) (Scheme 4c). Naphthalene 9 is expected to be the major product in the case of an ionic mechanism. In contrast, if the reaction occurs via a one-electron process, the predominant product should be 10, since 8 has a higher reduction potential $(-2.03 \mathrm{~V}$ against $-2.17 \mathrm{~V}$ for 7 versus SCE in DMF). ${ }^{23,}{ }^{24}$ The near exclusive formation of 1 -(phenylsulfonyl)naphthalene $(9,51 \%)$ further supports a two-electron mechanism.

These first experimental observations also validate the possible involvement of a $\mathrm{Cu}(\mathrm{I})$ sulfinate complex. To propose a complete plausible mechanism for the formation of diarylsulfones and understand which step is controlling its kinetics, DFT calculations were carried out (Scheme 5).

In presence of one equivalent of fluoride anions, a fluoride copper species is likely to be formed $(\mathbf{A} \rightarrow \mathbf{C}$, $\left.\Delta G=-3.2 \mathrm{kcal} \cdot \mathrm{mol}^{-1}\right)$ to then proceed to the transmetalation with the organosilane. ${ }^{25}$ Although it has already been reported and experimentally evidenced that a stable $\mathrm{FSO}_{2}{ }^{-}$anion is formed from DABSO and fluoride anions, ${ }^{7,26}$ this adduct can also serve as a fluoride transfer agent to generate a copper(I) fluoride complex. As regards the transmetalation between the silane and the $\mathrm{Cu}-\mathrm{F}$ species, computational results show a more favored transition state when the fluoride anion is in axial position on the silicon center $\left(\mathbf{C} \rightarrow \mathbf{D}, \Delta G^{\ddagger}\left(\mathbf{T S}_{2}\right)=19.2 \mathrm{kcal} \cdot \mathrm{mol}^{-1} v s \Delta G^{ \pm}\left(\mathbf{T S}_{2}{ }^{\prime}\right)=24.9 \mathrm{kcal} \cdot \mathrm{mol}^{-1}\right.$ for the equatorial position, see ESI). After coordination to the metallic center $\left(\mathbf{D} \rightarrow \mathbf{E}, \Delta G=-3.4 \mathrm{kcal} \cdot \mathrm{mol}^{-1}\right), \mathrm{SO}_{2}$ undergoes an exergonic 1,2-insertion in the $\mathrm{Cu}-\mathrm{C}$ bond, in accordance with the $\mathrm{S}_{E} 2$ mechanism reported in the literature $\left(E \rightarrow F, \Delta G=-11.9 \mathrm{kcal} \cdot \mathrm{mol}^{-1} ; \Delta G^{\neq}\left(\mathbf{T S}_{3}\right)=8.6 \mathrm{kcal} \cdot \mathrm{mol}^{-1}\right) .{ }^{27-30}$ While usually an apparent $1,1-$ insertion is observed because of the rearrangement to the more thermodynamically favored $S$ sulfinate, ${ }^{31,32}$ the $O$-sulfinate is here found to be lower in energy. However, the dimer with $S, O$ coordination $\mathbf{G}$ is the lowest energy isomer, in agreement with the obtained crystal structure of compound 4 (see SI for details). The coupling with the electrophile can then take place from both $O$ - or $S$-coordinated species. As experimental studies suggested, the ionic mechanism was considered for this step. The oxidative addition is more favored with an $\mathrm{O}$-coordination of the sulfinate (From $\mathbf{G}$, $\Delta G^{\ddagger}\left(\mathbf{T S}_{4 \mathrm{a}}\right)=14.5 \mathrm{kcal} \cdot \mathrm{mol}^{-1}$ against $\Delta G^{\ddagger}\left(\mathbf{T S}_{4 \mathrm{~b}}\right)=19.4 \mathrm{kcal} \cdot \mathrm{mol}^{-1}$ for the $S$-coordination). However, by contrast, the 4-center reductive elimination resulting from $O$-coordination lies at $+39.2 \mathrm{kcal} \cdot \mathrm{mol}^{-1}\left(\mathbf{T S}_{5 \mathrm{~b}}\right)$ 
with respect to the copper-sulfinate dimer $\mathbf{G}$ and has to be discarded in favor of $\mathbf{T S}_{5 \mathrm{a}}$ associated with $S$ coordination.

From this mechanism, the reductive elimination step seems to be kinetically determining $\left(\Delta G^{\ddagger}\left(\mathbf{T S}_{5 \mathrm{a}}\right)=\right.$ $25.6 \mathrm{kcal} \cdot \mathrm{mol}^{-1}$ with respect to $\mathbf{G}$ ), which could explain the higher yields obtained with electrophiles bearing electron-donating groups (3a-g, 87-60\%) than with withdrawing one (3i-p, 64-35\%). Besides, the low barrier associated with the insertion of sulfur dioxide justifies the absence of any direct $\mathrm{C}-\mathrm{C}$ cross-coupling and the efficient conversion of stoichiometric quantities of DABSO. Finally, it is noteworthy that the reductive elimination lies somewhat higher than the oxidative addition (here $\Delta \Delta G^{\ddagger}$ $\left.=6.4 \mathrm{kcal} \cdot \mathrm{mol}^{-1}\right)$, which is unusual for a $\mathrm{Cu}(\mathrm{I}) / \mathrm{Cu}(\mathrm{III})$ cycle.$^{15}$

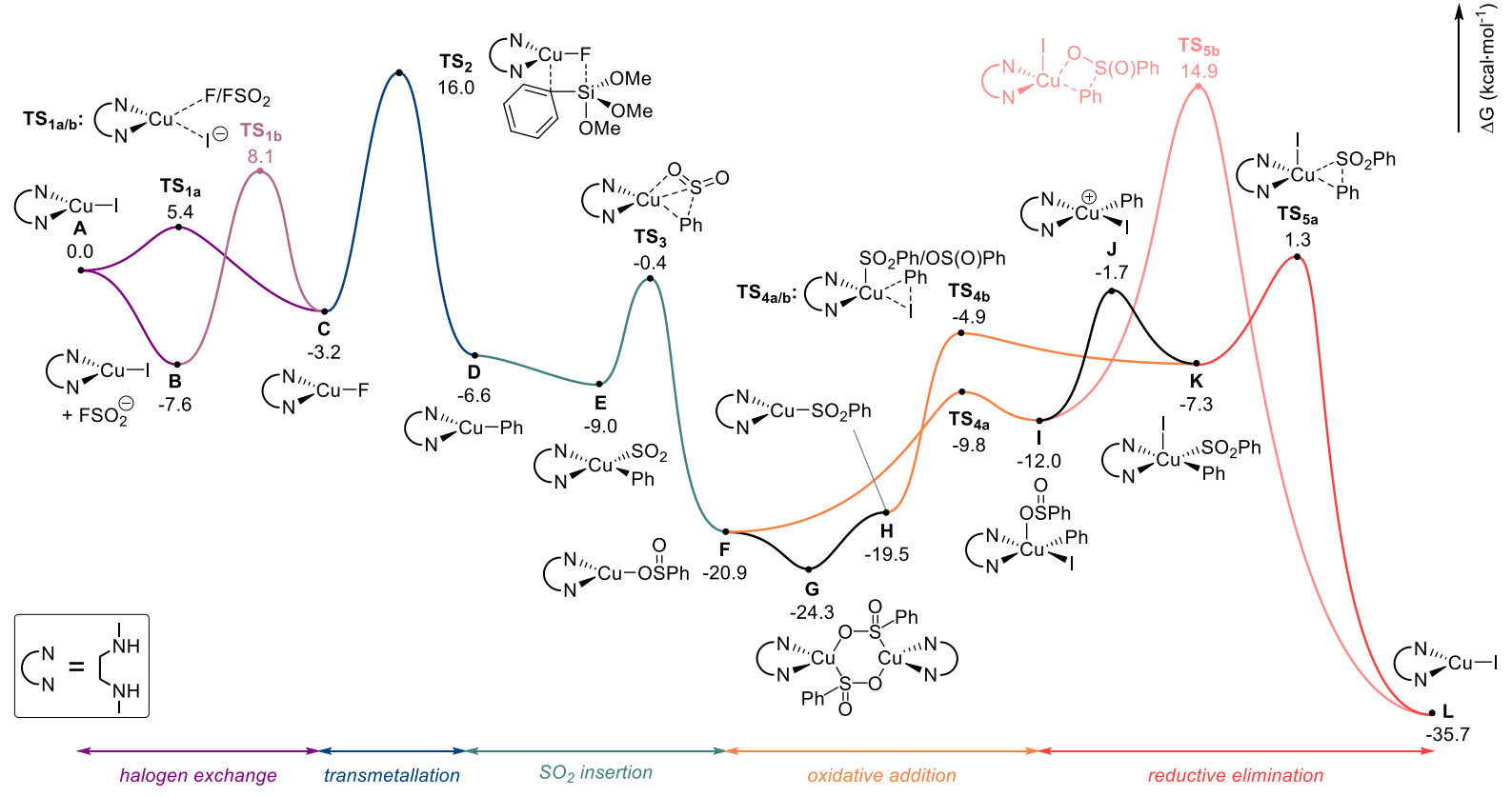

Scheme 5. DFT-calculated energy profile for the reaction. Level of theory: B3LYP-D3/6-311+G(d) $(C, H, O, N, F), 6-311++G(d, p)$ (S, Si), SDD for $\mathrm{Cu}$ and def2-TZVP for I, PCM was used for $\mathrm{CH}_{3} \mathrm{CN}$ solvation. Given values correspond to Gibbs free energies (in $\mathrm{kcal} \cdot \mathrm{mol}^{-1}$ ). Since $\mathrm{SO}_{2}$ decoordinates from $\mathrm{DABCO}$ without any transition state, free $\mathrm{SO}_{2}$ was considered to compute transition states.

\section{Conclusion}

In conclusion, we have described an efficient route to diaryl sulfones from readily available and easy to handle organosilanes, aryl halides and DABSO. This air-tolerant process is attractive as it involves inexpensive $\left[\mathrm{Cu}(\mathrm{MeCN})_{4}\right] \mathrm{BF}_{4}$ and $\mathrm{dmeda}$, and is compatible with a variety of functional groups on both coupling partners. Both experimental and theoretical studies support the mechanistic hypotheses for this process of a non-radical Hiyama cross-coupling with fast insertion of $\mathrm{SO}_{2}$ into a $\mathrm{Cu}(\mathrm{I})-\mathrm{Ar}$ intermediate.

\section{Acknowledgements}

We thank the CEA, CNRS, ERC (Consolidator Grant n 818260), GENCl for computing time (Allocation $\left.\mathrm{n}^{\circ} \mathrm{A} 0100806494\right)$, and Institut de France for funding.

\section{References}

1.Johansson Seechurn, C. C. C.; Kitching, M. O.; Colacot, T. J.; Snieckus, V., Palladium-Catalyzed Cross-Coupling: A Historical Contextual Perspective to the 2010 Nobel Prize. Angew. Chem. Int. Ed. 2012, 51 (21), 5062-5085.

2.Wu, X.-F.; Neumann, H.; Beller, M., Palladium-catalyzed carbonylative coupling reactions between Ar-X and carbon nucleophiles. Chem. Soc. Rev. 2011, 40 (10), 4986-5009. 
3.Chen, Y.; Willis, M. C., Copper(i)-catalyzed sulfonylative Suzuki-Miyaura cross-coupling. Chem. Sci. 2017, 8 (4), $3249-3253$. 4.Liu, N. W.; Liang, S.; Manolikakes, G., Recent Advances in the Synthesis of Sulfones. Synthesis 2016, 48 (13), $1939-1973$. 5.Trost, B. M.; Kalnmals, C. A., Sulfones as Chemical Chameleons: Versatile Synthetic Equivalents of Small-Molecule Synthons. Chem. Eur. J. 2019, 25 (48), 11193-11213.

6.Nakao, Y.; Hiyama, T., Silicon-based cross-coupling reaction: an environmentally benign version. Chem. Soc. Rev. 2011, 40 (10), 4893-4901.

7.Adenot, A.; Char, J.; von Wolff, N.; Lefèvre, G.; Anthore-Dalion, L.; Cantat, T., SO2 conversion to sulfones: development and mechanistic insights of a sulfonylative Hiyama cross-coupling. Chem. Commun. 2019, 55 (86), 12924-12927.

8.Zheng, D.; Mao, R.; Li, Z.; Wu, J., A copper(i)-catalyzed three-component reaction of triethoxysilanes, sulfur dioxide, and alkyl halides. Org. Chem. Front. 2016, 3 (3), 359-363.

9.Zhu, W.; Ma, D., Synthesis of Aryl Sulfones via I-Proline-Promoted Cul-Catalyzed Coupling Reaction of Aryl Halides with Sulfinic Acid Salts. J. Org. Chem. 2005, 70 (7), 2696-2700.

10.Woolven, H.; González-Rodríguez, C.; Marco, I.; Thompson, A. L.; Willis, M. C., DABCO-Bis(sulfur dioxide), DABSO, as a Convenient Source of Sulfur Dioxide for Organic Synthesis: Utility in Sulfonamide and Sulfamide Preparation. Org. Lett. 2011, 13 (18), 4876-4878.

11.Deeming, A. S.; Emmett, E. J.; Richards-Taylor, C. S.; Willis, M. C., Rediscovering the Chemistry of Sulfur Dioxide: New Developments in Synthesis and Catalysis. Synthesis 2014, 46 (20), 2701-2710.

12.Emmett, E. J.; Willis, M. C., The Development and Application of Sulfur Dioxide Surrogates in Synthetic Organic Chemistry. Asian J. Org. Chem. 2015, 4 (7), 602-611.

13.Jiang, Y.; Xu, L.; Zhou, C.; Ma, D., CHAPTER $1 \mathrm{Cu}$ - Catalyzed Ullmann - Type C-Heteroatom Bond Formation: The Key Role of Dinucleating Ancillary Ligands. In $\mathrm{C}-\mathrm{H}$ and $\mathrm{C}-\mathrm{X}$ Bond Functionalization: Transition Metal Mediation, The Royal Society of Chemistry: 2013; pp 1-45.

14.Klapars, A.; Huang, X.; Buchwald, S. L., A General and Efficient Copper Catalyst for the Amidation of Aryl Halides. J. Am. Chem. Soc. 2002, 124 (25), 7421-7428.

15.Zhang, S.-L.; Liu, L.; Fu, Y.; Guo, Q.-X., Theoretical Study on Copper(I)-Catalyzed Cross-Coupling between Aryl Halides and Amides. Organometallics 2007, 26 (18), 4546-4554.

16.Cheng, C.; Hartwig, J. F., Rhodium-Catalyzed Intermolecular C-H Silylation of Arenes with High Steric Regiocontrol. Science 2014, 343 (6173), 853.

17.Casitas, A.; Ribas, X., Insights into the Mechanism of Modern Ullmann-Goldberg Coupling Reactions. In Copper - Mediated Cross - Coupling Reactions, 2013; pp 253-279.

18.Creutz, S. E.; Lotito, K. J.; Fu, G. C.; Peters, J. C., Photoinduced Ullmann C-N Coupling: Demonstrating the Viability of a Radical Pathway. Science 2012, 338 (6107), 647.

19.de Gombert, A.; McKay, A. I.; Davis, C. J.; Wheelhouse, K. M.; Willis, M. C., Mechanistic Studies of the Palladium-Catalyzed Desulfinative Cross-Coupling of Aryl Bromides and (Hetero)Aryl Sulfinate Salts. J. Am. Chem. Soc. 2020, 142 (7), $3564-3576$. 20.Langs, D. A.; Hare, C. R., The structure of bis-(toluene-p-sulphinato)copper(II) tetrahydrate. Chem. Commun. 1967, (17), 853854.

21.Abeywickrema, A. N.; Beckwith, A. L. J., Rate constants for the cyclisation of some aryl radicals bearing unsaturated orthosubstituents. J. Chem. Soc., Chem. Commun. 1986, (6), 464-465.

22.Annunziata, A.; Galli, C.; Marinelli, M.; Pau, T., Determination of Rate Constants for the Reaction of Aryl Radicals with Enolate lons. Eur. J. Org. Chem. 2001, 2001 (7), 1323-1329.

23.Tye, J. W.; Weng, Z.; Johns, A. M.; Incarvito, C. D.; Hartwig, J. F., Copper Complexes of Anionic Nitrogen Ligands in the Amidation and Imidation of Aryl Halides. J. Am. Chem. Soc. 2008, 130 (30), 9971-9983.

24.Enemærke, R. J.; Christensen, T. B.; Jensen, H.; Daasbjerg, K., Application of a new kinetic method in the investigation of cleavage reactions of haloaromatic radical anions. J. Chem. Soc., Perkin Trans. 22001, (9), 1620-1630.

25.Gurung, S. K.; Thapa, S.; Kafle, A.; Dickie, D. A.; Giri, R., Copper-Catalyzed Suzuki-Miyaura Coupling of Arylboronate Esters: Transmetalation with (PN)CuF and Identification of Intermediates. Org. Lett. 2014, 16 (4), 1264-1267.

26.von Wolff, N.; Char, J.; Frogneux, X.; Cantat, T., Synthesis of Aromatic Sulfones from SO2 and Organosilanes Under Metalfree Conditions. Angew. Chem. Int. Ed. 2017, 56 (20), 5616-5619.

27.Fong, C. W.; Kitching, W., Sulfur dioxide insertion into aryl carbon—tin bonds: kinetics and mechanism. J. Organomet. Chem. 1973, 59, 213-223.

28.Kitching, W.; Fong, C. W., Kinetics and mechanism of sulfur dioxide insertion into carbon-tin bonds. J. Am. Chem. Soc. 1971, 93 (15), 3791-3792.

29.Jacobson, S. E.; Reich-Rohrwig, P.; Wojcicki, A., Intermediacy of O-sulphinates in the reaction of transition-metal carbonyl alkyls and aryls with sulphur dioxide. J. Chem. Soc. D 1971, (23), 1526-1527.

30.Jacobson, S. E.; Wojcicki, A., Kinetics and mechanism of sulfur dioxide insertion in pentahapto-(substituted and unsubstituted cyclopentadienyl)alkyl(and -aryl)dicarbonyliron(II) complexes. J. Am. Chem. Soc. 1973, 95 (21), 6962-6970.

31.Jacobson, S. E.; Reich-Rohrwig, P.; Wojcicki, A., Sulfur dioxide insertion. XVII. Linkage isomerism of transition metal-sulfinato complexes. Intermediacy of O-sulfinates in sulfur dioxide insertion reactions. Inorg. Chem. 1973, 12 (4), 717-723.

32.Wojcicki, A., Insertion Reactions of Transition Metal-Carbon $\sigma$-Bonded Compounds II. Sulfur Dioxide and Other Molecules. In Adv. Organomet. Chem., Stone, F. G. A.; West, R., Eds. Academic Press: 1974; Vol. 12, pp 31-81. 